\title{
Comparison of internal target volumes defined on 3-dimensional, 4-dimensonal, and cone-beam CT images of non-small-cell lung cancer
}

This article was published in the following Dove Press journal:

OncoTargets and Therapy

17 November 2016

Number of times this article has been viewed

\section{Fengxiang $\mathrm{Li}^{\prime}$ \\ Jianbin $\mathrm{Li}^{1}$ \\ Zhifang $\mathrm{Ma}^{\prime}$ \\ Yingjie Zhang' \\ Jun Xing \\ Huanpeng $\mathrm{Qi}^{\prime}$ \\ Dongping Shang ${ }^{2}$}

'Department of Radiation Oncology, ${ }^{2}$ Department of Big Bore CT Room, Shandong Cancer Hospital Affiliated to Shandong University, Shandong Academy of Medical Sciences, Jinan, Shandong, People's Republic of China
Purpose: The purpose of this study was to compare the positional and volumetric differences of internal target volumes defined on three-dimensional computed tomography (3DCT), four-dimensional CT (4DCT), and cone-beam CT (CBCT) images of non-small-cell lung cancer (NSCLC).

Materials and methods: Thirty-one patients with NSCLC sequentially underwent 3DCT and 4DCT simulation scans of the thorax during free breathing. The first CBCT was performed and registered to the planning $\mathrm{CT}$ using the bony anatomy registration during radiotherapy. The gross tumor volumes were contoured on the basis of 3DCT, maximum intensity projection (MIP) of 4DCT, and CBCT. CTV 3 (clinical target volume), internal target volumes, ITV $_{\text {MIP }}$ and $\mathrm{ITV}_{\mathrm{CBCT}}$, were defined with a $7 \mathrm{~mm}$ margin accounting for microscopic disease. ITV $_{10 \mathrm{~mm}}$ and $\mathrm{ITV}_{5 \mathrm{~mm}}$ were defined on the basis of $\mathrm{CTV}_{3 \mathrm{D}}: \mathrm{ITV}_{10 \mathrm{~mm}}$ with a $5 \mathrm{~mm}$ margin in left-right (LR), anterior-posterior (AP) directions and $10 \mathrm{~mm}$ in cranial-caudal (CC) direction; ITV I $_{\mathrm{mm}}$ with an isotropic internal margin (IM) of $5 \mathrm{~mm}$. The differences in the position, size, Dice's similarity coefficient (DSC) and inclusion relation of different volumes were evaluated.

Results: The median size ratios of $\mathrm{ITV}_{10 \mathrm{~mm}}, \mathrm{ITV}_{5 \mathrm{~mm}}$, and ITV $\mathrm{IIP}_{\mathrm{M}}$ to ITV $\mathrm{IBCT}_{\mathrm{C}}$ were 2.33, 1.88, and 1.03 , respectively, for tumors in the upper lobe and $2.13,1.76$, and 1.1, respectively, for tumors in the middle-lower lobe. The median DSCs of ITV $_{10 \mathrm{~mm}}, \mathrm{ITV}_{5 \mathrm{~mm}}, \mathrm{ITV}_{\mathrm{MIP}}$, and $\mathrm{ITV}_{\mathrm{CBCT}}$ were $0.6,0.66$, and 0.83 for all patients. The median percentages of ITV ${ }_{\text {СBCT }}$ not included in ITV $\mathrm{TV}_{10 \mathrm{~mm}}, \mathrm{ITV}_{5 \mathrm{~mm}}$, and ITV $_{\text {MIP }}$ were $0.1 \%, 1.63 \%$, and $15.21 \%$, respectively, while the median percentages of ITV $10 \mathrm{~mm}$, $\mathrm{ITV}_{5 \mathrm{~mm}}$, and $\mathrm{ITV}_{\text {MIP }}$ not included in $\mathrm{ITV}_{\text {CBCT }}$ were $57.08 \%, 48.89 \%$, and $20.04 \%$, respectively.

Conclusion: The use of the individual ITV derived from 4DCT merely based on bony registration in radiotherapy may result in a target miss. The ITVs derived from 3DCT with isotropic margins have a good coverage of the ITV from CBCT, but the use of those would result in a high proportion of normal tissue being irradiated unnecessarily.

Keywords: non-small-cell lung cancer, cone-beam CT, four-dimensional CT, three-dimensional $\mathrm{CT}$, internal target volume, volume comparison

\section{Introduction}

Accurate target definition is essential for high precision radiation therapy (HPRT) of non-small-cell lung cancer (NSCLC). ${ }^{1,2}$ Respiration-induced tumor motion not only reduces the accuracy of target delineation on volumetric images but increases the uncertainty in treatment planning and delivery. ${ }^{3}$ It is extraordinarily important to account for tumor motion in target definition.

For conventional treatment planning based on three-dimensional computed tomography (3DCT), a population-based margin is used to estimate tumor motion, 
which would result in a high proportion of normal tissue being irradiated unnecessarily or a geometric miss. ${ }^{4}$ Fourdimensional CT (4DCT) is commonly used to access tumor motion throughout respiratory cycle. The individual internal target volumes (ITVs) were generated based on 10 phases or maximum intensity projection (MIP) of 4DCT. ${ }^{5,6}$ Although the use of 4DCT ITVs significantly reduces target volumes in treatment planning compared to 3DCT ITVs, ${ }^{4,7}$ researchers question the accuracy of 4DCT ITVs ${ }^{8,9}$ since they are not sure whether the individual ITVs acquired in simulation accord with the real targets in radiation delivery.

The scan time of cone-beam CT (CBCT) mounted on the gantry of accelerator takes more than $60 \mathrm{~s}$ and spans several respiratory cycles. Individual online ITVs can be generated based on CBCT images. ${ }^{10,11}$ The use of CBCT for online setup corrections has been confirmed. However, because of rapid development of HPRT, merely using CBCT for setup corrections has not met our demands. There is growing interest in the use of CBCT images in image-guided radiation therapy and adaptive radiation therapy including CBCT-based target delineation, target definition, dose calculation, and so on. ${ }^{12-15}$

In the present study, the differences in target position, volume, similarity, and inclusion relation of the conventional ITVs defined on 3DCT, the individual ITV on the MIP of 4DCT, and the individual online ITV on CBCT were analyzed. The aim of this study was to evaluate the accuracy of ITVs defined on 3DCT and 4DCT and investigate the use of CBCT combined with 3DCT and 4DCT in the definition of target volumes.

\section{Materials and methods}

\section{Patient characteristics}

Thirty-one patients with peripheral NSCLC underwent axial 3DCT and 4DCT simulation scanning for treatment planning between March 2010 and May 2015 in Shandong Cancer Hospital affiliated to Shandong University. The study was approved by the Institutional Review Board. All the patients provided written informed consent prior to treatment planning. Patient and tumor characteristics are listed in Table 1.

\section{CT simulation and image acquisition}

During simulation, all the patients were immobilized using vacuum bags in the supine position with the arms raised above the head. For each patient, an axial 3DCT scan of the thoracic region was performed, followed by a 4DCT scan during free breathing on Brilliance Bores CT simulator
Table I Patient and tumor characteristics

\begin{tabular}{ll}
\hline Gender & \\
Male & 14 \\
Female & 17 \\
Age, years & \\
Range & $36-79$ \\
Mean/median & $62 / 63$ \\
Location & \\
RUL & 8 \\
RML/RLL & 7 \\
LUL & 9 \\
LLL & 7 \\
T stage & \\
TI & 21 \\
T2 & 7 \\
T3 & 3 \\
Histology & \\
SCC & 8 \\
Adenocarcinoma & 23 \\
\hline
\end{tabular}

Abbreviations: RUL, right upper lobe; RML, right middle lobe; RLL, right lower lobe; LUL, left upper lobe; LLL, left lower lobe; SCC, squamous cell carcinoma.

(Philips Medical Systems, Highland Heights, OH, USA). The 3DCT and 4DCT acquisition protocols have been reported in a previous study. ${ }^{4}$ The 4 DCT images were sorted into 10 bins according to the phase of the breathing signal. MIPs of the 4DCT data sets were then generated, which contain the maximum Hounsfield unit (HU) in each geometric voxel across all time-resolved data sets. ${ }^{6,16}$ All the CT images were reconstructed with a thickness of $3 \mathrm{~mm}$ and then transferred to Eclipse treatment planning system (Eclipse 8.6; Varian Medical Systems, Palo Alto, CA, USA). For all the patients, three-dimensional conformal radiotherapy or intensity-modulated radiation therapy treatment planning was performed on the basis of 3DCT.

\section{Online image acquisition}

On the linear accelerator, the patients were aligned according to the skin tattoos by using the in-room laser system. The CBCT images were acquired with the gantry-mounted onboard imager (Varian Medical Systems). The first CBCT image was acquired immediately after setup. The scan time takes $\sim 60 \mathrm{~s}$, and $\sim 6502 \mathrm{D} \mathrm{kV}$ images are captured during the full $360^{\circ}$ rotation. CBCT images were reconstructed with a thickness of $2.5 \mathrm{~mm}$. The CBCT scan was rigidly registered to the planning $\mathrm{CT}$ scan. An automatic registration of the bony anatomy was performed using a user-defined region of interest including the spinal cord. The registration was evaluated by the radiation therapists and manually corrected if necessary. Then, the registered CBCT images were automatically transferred to Eclipse treatment planning system. 


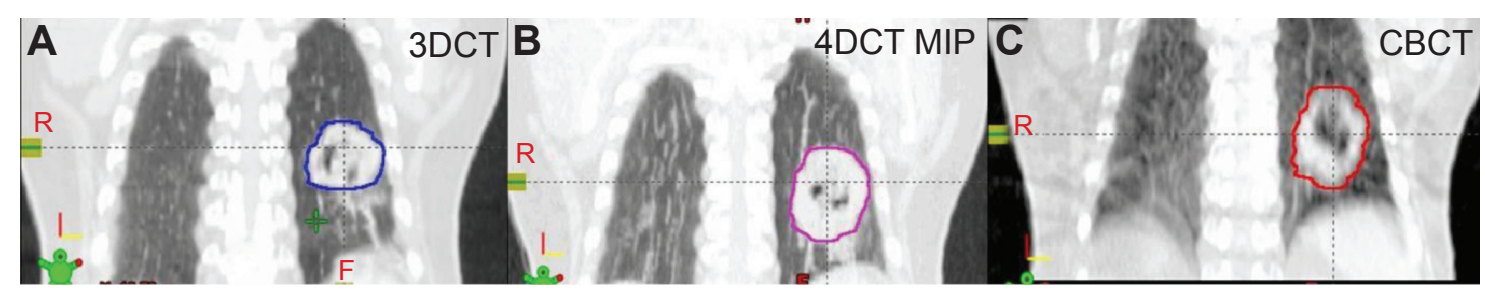

Figure I Example (Patient 19) of the different target volumes: (A) GTV (blue line) derived from 3DCT, (B) GTV (magenta line) derived from 4DCT MIP, and (C) GTV (red line) derived from CBCT.

Abbreviations: CBCT, cone-beam computed tomography; 3DCT, three-dimensional computed tomography; 4DCT, four-dimensional computed tomography; GTV, gross tumor volumes; MIP, maximum intensity projection.

\section{Target delineation}

The gross tumor volumes (GTVs) were manually delineated on 3DCT, CBCT, 10 phases, and MIP of the 4DCT and by a radiation oncologist. The targets were delineated according to the following protocol: 1) The GTVs were delineated using lung window setting (window width: 1,600 HU and window level: $-600 \mathrm{HU})$. 2) The use of the mediastinum window $(40 / 400 \mathrm{HU})$ was allowed for information purposes to avoid the inclusion of adjacent vessels and mediastinal or chest wall structures. ${ }^{12}$ 3) Blurring in the periphery of the tumor, representing the "partial volume effect" and "partial projection effect for moving objects," was included in the GTVs. ${ }^{17}$ The GTVs contoured on the basis of 3DCT, 4DCT, MIP, and CBCT of Patient 19 showed in Figure 1.

\section{Definition of PTVs}

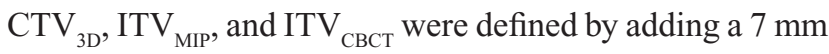
margin to GTVs delineated on 3DCT, 4DCT, MIP, and CBCT accounting for microscopic disease. $\mathrm{ITV}_{10 \mathrm{~mm}}$ and $\mathrm{ITV}_{5 \mathrm{~mm}}$ were defined on the basis of $\mathrm{CTV}_{3 \mathrm{D}}: \mathrm{ITV}_{10 \mathrm{~mm}}$ with a $5 \mathrm{~mm}$ margin in LR, AP directions, and $10 \mathrm{~mm}$ in $\mathrm{CC}$ direction; $\mathrm{ITV}_{5 \mathrm{~mm}}$ with an isotropic internal margin (IM) of $5 \mathrm{~mm}$.

\section{Tumor motion}

The coordinates in left-right (LR), anterior-posterior (AP), and cranial-caudal (CC) directions of the center of mass (COM) of GTVs in 10 phases of 4DCT were measured. The peak-to-peak displacement of COM in three directions was calculated on the basis of the coordinates, which represents the tumor motion. The $3 \mathrm{D}$ motion vector (vector) of $\mathrm{COM}$ was calculated as follows:

$$
\text { Vector }=\sqrt{\mathrm{LR}^{2}+\mathrm{AP}^{2}+\mathrm{CC}^{2}}
$$

\section{Comparison of ITVs}

Position, volume, Dice's similarity coefficient (DSC), ${ }^{2}$ and inclusion relation between $\mathrm{ITV}_{10 \mathrm{~mm}}, \mathrm{ITV}_{5 \mathrm{~mm}}, \mathrm{ITV}_{\mathrm{MIP}}$, and ITV were compared, respectively. Positions of ITVs are represented by COM coordinates. The DSC of volume A and B is defined as the ratio of the volume of their intersection to their average volume, with a value of 1 indicating identical and 0 indicating no overlap of two volumes. The formula is as follows:

$$
\operatorname{DSC}(\mathrm{A}, \mathrm{B})=\frac{2(\mathrm{~A} \cap \mathrm{B})}{\mathrm{A}+\mathrm{B}}
$$

The percentage of B not included in A [Per (B not in A)] is used to indicate the inclusion relation between two volumes. Assumed volume A was reference for the real volume irradiated. If the treatment planning was based on volume $\mathrm{B}$, there would be Per (A not in $\mathrm{B}$ ) of volume A missing irradiation and Per (B not in $\mathrm{A}$ ) of volume $\mathrm{B}$ being irradiated unnecessarily. The formula is as follows:

$$
\operatorname{Per}(\mathrm{B} \text { not in } \mathrm{A})=1-\frac{\mathrm{A} \cap \mathrm{B}}{\mathrm{B}}
$$

\section{Statistical analysis}

Statistical analysis was performed using the SPSS 16.0 software package (SPSS Inc., Chicago, IL, USA). The Wilcoxon paired sum test was used for the comparison of tumor motion, position, volume, DSC, and inclusion relation. For the comparison of data between groups A and B, the Wilcoxon independent sum test was used. The Spearman sum test was used for correlation analysis. The level of significance was a two-sided $P$-value of $<0.05$ for all the tests.

\section{Results}

The tumor motions for groups A and B are presented in Table 2. The median tumor motion amplitude in 3D direction was $4 \mathrm{~mm}$ for group $\mathrm{A}$ and $11.2 \mathrm{~mm}$ for group $\mathrm{B}$, with a significant statistical difference $(P<0.001)$. Table 3 presents the centroid shifts between ITV $_{5 \mathrm{~mm}}$ (or ITV $10 \mathrm{~mm}$ ) and ITV $\mathrm{ITV}_{\mathrm{MIP}}$, and $\mathrm{ITV}_{\mathrm{CBCT}}$. Two related sample tests indicated 
Table 2 The tumor motion in the LR, AP and CC directions and $3 D$ directions for group $A$ and group $B$.

\begin{tabular}{lllll}
\hline Group \# & \multicolumn{4}{l}{ The tumor motion, $\mathbf{m m}$} \\
\cline { 2 - 5 } & LR & AP & CC & 3D \\
\hline Group A & I.4 (0.2-4.9) & $1.9(0.7-5)$ & $2.1(0.3-5.6)$ & $4.0(1.2-7)$ \\
Group B & $1.8(0.5-3)$ & $2.6(0.5-4.6)$ & $10.8(5-18.1)$ & $11.2(5.8-18.4)$ \\
z & -1.053 & -1.014 & -4.529 & -4.407 \\
P-value & 0.292 & 0.31 & $<0.001$ & $<0.00 \mathrm{I}$ \\
\hline
\end{tabular}

Note: Data are presented as median (range).

Abbreviations: AP, anterior-posterior; CC, cranial-caudal; LR, left-right.

the difference of centroid coordinates between $\mathrm{ITV}_{\text {MIP }}$ and $\mathrm{ITV}_{\mathrm{CBCT}}$ in LR direction, ITV $\mathrm{IT}_{5 \mathrm{~mm}}$ and ITV $\mathrm{IBCT}_{\mathrm{C}}$ in CC direction is approximately significant $(P=0.083$ and 0.07$)$.

ITV size and the size ratios of ITV $10 \mathrm{~mm}, \mathrm{ITV}_{5 \mathrm{~mm}}, \mathrm{ITV}_{\mathrm{MIP}}$ to $\mathrm{ITV}_{\mathrm{CBCT}}$ are listed in Table 4. A significant inverse correlation was found for the ratio of ITV $\mathrm{Imm}_{5 \mathrm{~mm}}$ to ITV $\mathrm{IBCT}_{\mathrm{CB}}$ to tumor motion vector for all the patients ( $r=-0.373, P=0.039)$.

Figure 2 illustrates the DSCs of $\mathrm{ITV}_{10 \mathrm{~mm}}$ and ITV $\mathrm{ITV}_{5 \mathrm{~mm}}$ and ITV $\mathrm{CBCT}_{\mathrm{CB}}$, and ITV $\mathrm{IIP}_{\mathrm{MI}}$ and ITV $\mathrm{CBCT}_{\mathrm{C}}$ for each patient. The median DSC of ITV $\mathrm{IIP}_{\text {IIP }}$ and $\mathrm{ITV}_{\mathrm{CBCT}}$ was 0.83 (range 0.61-0.92), which was greater than the DSC of $\mathrm{ITV}_{10 \mathrm{~mm}}$ and $\mathrm{ITV}_{\text {СВCT }}$ (median 0.60 and range $0.46-0.79 ; P<0.001$ ) and DSC of $\mathrm{ITV}_{5 \mathrm{~mm}}$ and $\mathrm{ITV}_{\mathrm{CBCT}}$ (median 0.66 and range $0.50-0.83 ; P<0.001)$. The DSCs of $\mathrm{ITV}_{10 \mathrm{~mm}}$ and $\mathrm{ITV}_{\mathrm{CBCT}}$, $\mathrm{ITV}_{5 \mathrm{~mm}}$ and $\mathrm{ITV}_{\mathrm{CBCT}}$, and ITV $\mathrm{IIP}_{\mathrm{MI}}$ and ITV correlation to tumor motion vector ( $P>0.05$, respectively).

The percentages of ITV $_{10 \mathrm{~mm}}, \mathrm{ITV}_{5 \mathrm{~mm}}$, and ITV $\mathrm{IIP}_{\text {M }}$ not included in $\mathrm{ITV}_{\mathrm{CBCT}}$ and the percentages of ITV in $\mathrm{ITV}_{10 \mathrm{~mm}}, \mathrm{ITV}_{5 \mathrm{~mm}}$, and $\mathrm{ITV}_{\text {MIP }}$ are presented in Table 5. Percentage of ITV $\mathrm{MIP}_{\text {IP }}$ not in ITV of $\operatorname{ITV}_{10 \mathrm{~mm}}$ not in $\operatorname{ITV}_{\text {СвCT }}(P<0.001)$ and percentage of $\mathrm{ITV}_{5 \mathrm{~mm}}$ not in $\operatorname{ITV}_{\mathrm{CBCT}}(P<0.001)$. Percentage of $\operatorname{ITV}_{\mathrm{CBCT}}$ not in ITV $_{10 \mathrm{~mm}}$ was less than percentage of ITV $_{\mathrm{CBCT}}$ not in $\operatorname{ITV}_{5 \mathrm{~mm}}(P<0.001)$ and percentage of ITV $\mathrm{IBCT}$ not in $\mathrm{ITV}_{\text {MIP }}$ $(P<0.001)$.

\section{Discussion}

The centroid shifts of targets could directly influence the DSC and the inclusion relation between targets. In the present study, the difference in centroid position between ITVs was initially evaluated. The relatively large standard deviation (SD) $(1.9-4.1 \mathrm{~mm})$ to the mean in centroid position indicated a great difference in the shifts of ITVs among individual patient. The large centroid shifts of ITVs in 3D direction (mean, $\sim 5 \mathrm{~mm}$ ) also demonstrated it. The centroid shifts of ITVs in CC direction were greater than the shifts in LR or AP direction $(P<0.05$, respectively), which indicated that the respiration-induced tumor motion could impact on the centroid shifts of targets due to the large tumor motion in CC direction. Additionally, using bony registration may increase the centroid shifts of ITVs. Wulf et $\mathrm{a}^{18}$ showed a poor correlation in the position between mobile soft tissue tumors and bony anatomy. The SDs of the shifts of mobile soft tissue tumors and the bony anatomy were $3.3,5.2$, and $4.5 \mathrm{~mm}$ in LR, AP, and CC directions, respectively. Yeung et $\mathrm{al}^{19}$ reported the difference in the couch shifts between bony and soft tissue registration was $5.4 \pm 5.7 \mathrm{~mm}$ in $3 \mathrm{D}$ direction.

4DCT has been considered as a reliable tool for assessing tumor motion. ${ }^{20,21}$ Comparing ITV $_{\text {CBCT }}$ size with ITV $_{\text {MIP }}$ contributes to evaluate the respiratory motion information encompassed in CBCT images. Our study indicated a median of $3 \%$ increase of ITV $_{\text {MIP }}$ size than ITV $_{\text {СBCT }}$ for group $\mathrm{A}(P=0.055)$ and a median of $10 \%$ increase for group $\mathrm{B}$ $(P=0.005)$. Recent data by other authors ${ }^{10,11}$ support this observation. Wang et a $1^{10}$ showed that the volumetric difference between ITVs from CBCT and 4DCT was within $8.7 \%$ and $8.0 \%$ for the phantom and clinical cases, respectively. Liu et $\mathrm{a}^{11}$ reported that the ITV from CBCT has a median $11.8 \%$ (range, -49.8 to $+24.3 \%, P<0.001$ ) reduction by the ITV derived from end-inhale and end-exhale respiratory phase of 4DCT. They found that the relative target motion

Table 3 Centroid shifts of ITV 5 mm $\left(\right.$ or ITV $10 \mathrm{~mm}$ ) and ITV ${ }_{\mathrm{CBCT}}$, ITV $\mathrm{MIP}_{\mathrm{P}}$ and ITV $\mathrm{CBCT}_{\text {in }}$ ine LR, AP and CC directions and 3D directions for group $A$ and group $B$

\begin{tabular}{|c|c|c|c|c|}
\hline Centroid shifts & LR & AP & CC & 3D \\
\hline $\mathrm{ITV}_{5 \mathrm{~mm}}($ or ITV $10 \mathrm{~mm})$ and ITV & $-0.2(-0.4 \pm 2.0)$ & $-0.6(-0.6 \pm 3.3)$ & $-1.2(-1.4 \pm 4.1)$ & $4.5(5.2 \pm 2.6)$ \\
\hline$I T V_{\text {MIP }}$ and ITV & $-0.2(-0.7 \pm 1.9)$ & $0.3(0.3 \pm 3.5)$ & $-0.4(-1.1 \pm 3.6)$ & $4.3(4.7 \pm 2.8)$ \\
\hline \multirow[t]{2}{*}{$z$} & -0.556 & -1.225 & -1.810 & - \\
\hline & -1.732 & -0.441 & -1.412 & - \\
\hline \multirow[t]{2}{*}{$P$-value } & -0.578 & 0.220 & 0.07 & - \\
\hline & 0.083 & 0.659 & 0.158 & - \\
\hline
\end{tabular}

Note: Data are presented as median and mean $\pm \mathrm{SD}, \mathrm{mm}$

Abbreviations: AP, anterior-posterior; CBCT, cone-beam computed tomography; CC, cranial-caudal; ITV, internal target volume; LR, left-right; MIP, maximum intensity projection. 
Table 4 ITV size and the size ratios of ITV $10 \mathrm{~mm}$ to ITV ${ }_{\mathrm{CBCT}}$, ITV $5 \mathrm{~mm}$ to ITV ${ }_{\mathrm{CBCT}}$, and ITV ${ }_{\text {MIP }}$ to ITV ${ }_{\mathrm{CBCT}}$

\begin{tabular}{|c|c|c|c|c|c|c|c|}
\hline Group & $\begin{array}{l}\text { ITV } \\
\left(\mathrm{cm}_{10 \mathrm{~mm}}\right)\end{array}$ & 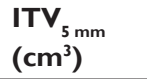 & $\begin{array}{l}I_{\text {ITV }} \\
\left(\mathrm{cm}^{3}\right)\end{array}$ & $\begin{array}{l}\text { ITV }_{\text {CBCT }} \\
\left(\mathrm{cm}^{3}\right)\end{array}$ & $I T V_{10 \mathrm{~mm}} / I T V_{\text {СBCT }}$ & ITV $_{5 \mathrm{~mm}} / I T V_{\mathrm{CBCT}}$ & ITV $_{\text {MIP }} /$ ITV $_{\text {СBCT }}$ \\
\hline \multicolumn{8}{|l|}{ Group A } \\
\hline Median & 74.71 & 61.6 & 30.9 & 32 & 2.33 & 1.88 & 1.03 \\
\hline Range & $26.3-254.1$ & $20.8-215.4$ & $8.52-62.1$ & $9.51-155.3$ & $1.64-3.27$ & I.39-2.48 & $0.88-1.29$ \\
\hline Mean \pm SD & $84.5 \pm 56.2$ & $69 \pm 47.97$ & $41.7 \pm 37.2$ & $39.5 \pm 35.3$ & $2.44 \pm 0.47$ & $1.95 \pm 0.31$ & $1.05 \pm 0.12$ \\
\hline$P$ (comp to ITV & $<0.00$ I & $<0.00$ I & 0.055 & - & - & - & - \\
\hline \multicolumn{8}{|l|}{ Group B } \\
\hline Median & 63.5 & 52.4 & 31.6 & 29.6 & 2.13 & 1.76 & I.I \\
\hline Range & $30.3-240$ & $22.3-212.5$ & $|I .1-| 7 \mid .6$ & $|1.3-15| .4$ & $1.45-2.89$ & $1.28-2.19$ & $0.87-1.34$ \\
\hline Mean \pm SD & $88.5 \pm 68.9$ & $74.4 \pm 61.6$ & $53.6 \pm 53.4$ & $48 \pm 47.8$ & $2.17 \pm 0.42$ & $1.76 \pm 0.28$ & $1.1 I \pm 0.14$ \\
\hline$P$ (comp to ITV ${ }_{\mathrm{CBCT}}$ ) & 0.001 & 0.001 & 0.005 & - & - & - & - \\
\hline
\end{tabular}

Abbreviations: CBCT, cone-beam computed tomography; ITV, internal target volume; MIP, maximum intensity projection; SD, standard deviation.

was not the significant factor $(P=0.323)$ causing underestimation of ITV in CBCT. The present study also found the ratio of ITV $\mathrm{IIP}_{\mathrm{M}}$ to ITV $\mathrm{CBCT}_{\mathrm{C}}$ which showed no correlation with the motion vector $(P=0.153)$, and the difference of the ratio of

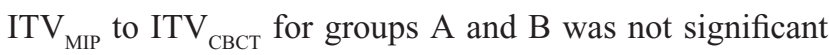
$(P>0.05)$. Therefore, the tumor motion could not impact the relative motion information included in $\mathrm{CBCT}$ compared to 4DCT. The CBCT images can be used to account for the individual online tumor motion well, but the motion information in CBCT is less than that in 4DCT.

Analyzing the DSC and inclusion relation of targets which integrate the position and size with shape information can reveal geometric features of different targets. ${ }^{2,4,5}$ This study indicated a good similarity between ITV $_{\text {MIP }}$ and ITV with a median DSC of 0.83 . Nonetheless, there would be a median of $15.21 \%$ of ITV ${ }_{\mathrm{CBCT}}$ missing irradiation and $20.04 \%$ ITV $_{\text {MIP }}$ being irradiated unnecessarily, if ITV $_{\text {MIP }}$ is used in the treatment planning. These results challenged the accuracy of the individual ITV defined on 4DCT. The difference in size did not significantly change the inclusion relation of targets, since $\mathrm{ITV}_{\mathrm{CBCT}}$ size has a median of only $6 \%$ decrease than ITV $_{\text {MIP }}$ for all patients. So the position and shape of targets may be the major factors influencing on the inclusion relation. Respiratory variations in simulation and radiation delivery could cause changes in the position and shape of targets. The registration error based on bony anatomy may increase the centroid shifts of targets. ${ }^{18,19}$ Therefore, expanding another margin/using soft tissue registration and visual rectification between planning $\mathrm{CT}$ and $\mathrm{CBCT}$ may improve the accuracy of 4DCT ITV. ${ }^{19,22,23}$

In addition, our data showed that $\mathrm{ITV}_{10 \mathrm{~mm}}$ and $\mathrm{ITV}_{5 \mathrm{~mm}}$ sizes were far larger than ITV $_{\text {СвCт }}$ for both groups. The large difference in size inevitably results in poor DSCs of

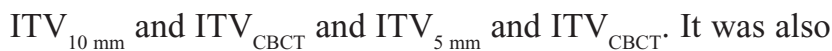

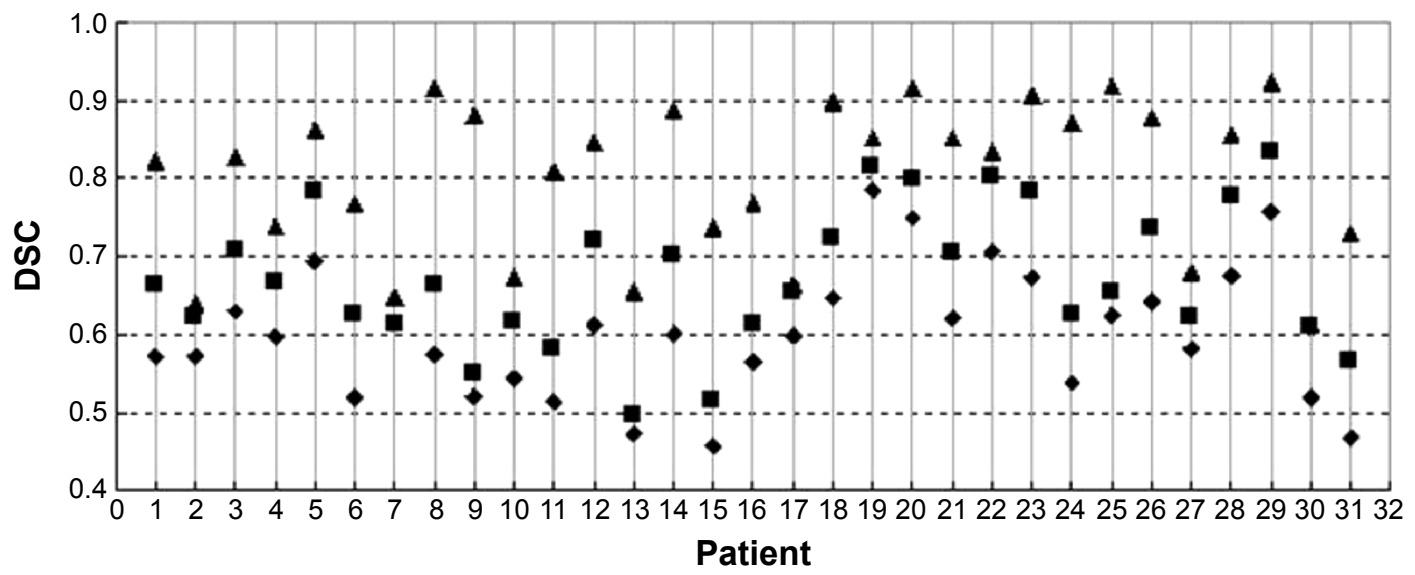

• DSC $\left(\right.$ ITV $\left._{10 \mathrm{~mm}}, \mathrm{ITV} \mathrm{CBCT}_{\mathrm{C} C}\right) \quad \mathrm{DSC}\left(\mathrm{ITV}_{5 \mathrm{~mm}}, \mathrm{ITV}_{\mathrm{CBCT}}\right) \wedge \mathrm{DSC}\left(\mathrm{ITV}_{\mathrm{MIP}}, \mathrm{ITV}_{\mathrm{CBCT}}\right)$



Abbreviations: $\mathrm{CBCT}$, cone-beam computed tomography; DSC, Dice's similarity coefficient; ITV, internal target volume; MIP, maximum intensity projection. 


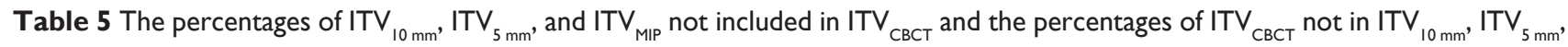
and ITV MIP

\begin{tabular}{|c|c|c|c|c|c|c|}
\hline Percentage & $\begin{array}{l}\text { ITV } \\
\text { in ITV } \text { ITV }_{10 \mathrm{~mm}} \\
\end{array}$ & $\begin{array}{l}\text { ITV } \\
\text { in ITV } \text { ITV }_{5 \mathrm{~mm}} \text { not }\end{array}$ & $\begin{array}{l}\text { ITV } \\
\text { in ITV } \text { ITV }_{\text {MIP }} \text { not }\end{array}$ & $\begin{array}{l}\text { ITV } \\
\text { in ITV } \\
\text { ITV } \\
\text { CBCT }\end{array}$ & $\begin{array}{l}\text { ITV }_{5 \mathrm{~mm}} \text { not } \\
\text { in ITV } \\
\text { CBCT }\end{array}$ & $\begin{array}{l}\text { ITV }_{\text {MIP }} \text { not } \\
\text { in ITV } \\
\text { IBCT }\end{array}$ \\
\hline Median & 0.1 & 1.63 & 15.21 & 57.08 & 48.89 & 20.04 \\
\hline Range & $0-13.88$ & $0-21.42$ & $4.23-34.01$ & $33.7-69.41$ & $27.45-64.44$ & $1.46-44.44$ \\
\hline Mean \pm SD & $1.98 \pm 3.58$ & $4.93 \pm 6.04$ & $16.93 \pm 9.36$ & $56.03 \pm 8.97$ & $47.48 \pm 10.01$ & $21.86 \pm 11.92$ \\
\hline
\end{tabular}

Abbreviations: $\mathrm{CBCT}$, cone-beam computed tomography; ITV, internal target volume; MIP, maximum intensity projection; SD, standard deviation.

found that there would be a median of $57.08 \%$ of $\mathrm{ITV}_{10 \mathrm{~mm}}$ or $48.89 \%$ of $\mathrm{ITV}_{5 \mathrm{~mm}}$ being irradiated unnecessarily if treatment planning was created on $\mathrm{ITV}_{10 \mathrm{~mm}}$ or ITV $\mathrm{Imm}_{5 \mathrm{~m}}$. The target size being irradiated unnecessarily was far larger than that when treatment planning was created on $\mathrm{ITV}_{\mathrm{MIP}}$. However, the risk of missing irradiation was very small if radiation delivery was based on $\mathrm{ITV}_{10 \mathrm{~mm}}$ or ITV $\mathrm{ITm}_{5 \mathrm{~m}}$, with a median of $0.1 \%$ of $\mathrm{ITV}_{10 \mathrm{~mm}}$ or $1.63 \%$ of $\mathrm{ITV}_{5 \mathrm{~mm}}$ missing irradiation.

For group $\mathrm{A}$, the median percentage of $\mathrm{ITV}_{\mathrm{CBCT}}$ not in $\mathrm{ITV}_{5 \mathrm{~mm}}$ was $1.24 \%$ (range, $0 \%-17.88 \%$ ), and the median tumor motion in $\mathrm{CC}$ direction was $2.1 \mathrm{~mm}$. It is reasonable to add a $5 \mathrm{~mm}$ margin in $\mathrm{CC}$ direction accounting for tumor motion. The median percentage of $\mathrm{ITV}_{\mathrm{CBCT}}$ not in $\mathrm{ITV}_{5 \mathrm{~mm}}$ was $5.8 \%$ (range, $0 \%-21.42 \%$ ) for group $\mathrm{B}$, which was not significantly greater than that for group A $(P=0.404)$. Hence, it is feasible to add a $5 \mathrm{~mm}$ margin in $\mathrm{CC}$ direction for tumors in the middle-lower lobe in most cases. But using a $5 \mathrm{~mm}$ margin should be cautious for tumors with large motion due to the negative correlation between the ratio of $\mathrm{ITV}_{5 \mathrm{~mm}}$ to $\operatorname{ITV}_{\mathrm{CBCT}}$ and tumor motion $(r=-0.373, P=0.039)$.

The ITVs derived from 3DCT based on isotropic margins have a good coverage of on time tumor motion, which have no special requirement for the pattern of registration. But the ITVs are not suitable for Stereotactic body radiotherapy (SBRT) due to a high proportion of normal tissue being possibly irradiated unnecessarily. The individual ITV from 4DCT can usually encompass the tumor motion in treatment. However, its usage is required for soft tissue registration and visual rectification. The individual ITV can be used for highly precise SBRT, which can increase the biological dose effect of radiation and the local tumor control rate.

It should be noted that the poor quality of CBCT images may increase the delineation error. This study established a strict delineation standard, and all the delineations were performed by an oncologist in order to reduce error. The ITVs delineated based on CBCT and MIP images may not fully encompass the tumor motion if an adjacent structure has equal or greater density. ${ }^{11,16}$ In addition, the ITVs may be underestimated in both 4DCT and CBCT images due to irregular breathing patterns. ${ }^{23,24}$

\section{Conclusion}

In the present study, the CBCT can encompass tumor motion well, but the respiratory motion information included in CBCT is less than that in 4DCT. The individual ITV derived from 4DCT can generally encompass the tumor motion in treatment, but the use of it in radiotherapy merely based on bony registration may result in a target miss. The ITVs from 3DCT with isotropic margins have a good coverage of tumor motion, while use of it may lead to a high proportion of normal tissue being irradiated unnecessarily. It may be feasible to generate the population-based ITV with an isotropic IM of $5 \mathrm{~mm}$ for tumors in the middle-lower lobe in most cases.

\section{Disclosure}

The authors report no conflicts of interest in this work.

\section{References}

1. Li G, Citrin D, Camphausen K, et al. Advances in 4D medical imaging and 4D radiation therapy. Technol Cancer Res Treat. 2008;7: 67-81.

2. van Dam IE, van Sörnsen de Koste JR, Hanna GG, et al. Improving target delineation on 4-dimensional CT scans in stage I NSCLC using a deformable registration tool. Radiother Oncol. 2010;96:67-72.

3. Purdie TG, Moseley DJ, Bissonnette JP, et al. Respiration correlated cone-beam computed tomography and 4DCT for evaluating target motion in Stereotactic Lung Radiation Therapy. Acta Oncol. 2006;45: 915-922.

4. Li FX, Li JB, Xing J, et al. Analysis of the advantage of individual PTVs defined on axial 3D CT and 4D CT images for liver cancer. J Appl Clin Med Phys. 2012;13:62-71.

5. Ezhil M, Vedam S, Balter P, et al. Determination of patient-specific internal gross tumor volumes for lung cancer using four-dimensional computed tomography. Radiat Oncol. 2009;4.

6. Muirhead R, McNee SG, Featherstone C, et al. Use of Maximum Intensity Projections (MIPs) for target outlining in 4DCT radiotherapy planning. J Thorac Oncol. 2008;3:1433-1438.

7. Li FX, Li JB, Zhang YJ, et al. Comparison of the planning target volume based on three-dimensional CT and four-dimensional CT images of non-small-cell lung cancer. Radiother Oncol. 2011;99:176-180.

8. Britton KR, Starkschall G, Tucker SL, et al. Assessment of gross tumor volume regression and motion changes during radiotherapy for non-small-cell lung cancer as measured by four-dimensional computed tomography. Int J Radiat Oncol Biol Phys. 2007;68:1036-1046.

9. James SS, Mishra P, Hacker F, et al. Quantifying ITV instabilities arising from 4DCT: a simulation study using patient data. Phys Med Biol. 2012;57:L1-L7.

10. Wang Z, Wu J, Marks LB, et al. Cone-beam CT localization of internal target volumes for stereotactic body radiotherapy of lung lesions. Int $J$ Radiat Oncol Biol Phys. 2007;69:1618-1624. 
11. Liu HW, Khan R, D'Ambrosi R, et al. The influence of target and patient characteristics on the volume obtained from cone beam CT in lung stereotactic body radiation therapy. Radiother Oncol. 2013;160: 312-316.

12. Altorjai G, Fotina I, Lütgendorf-Caucig C, et al. Cone-beam CT-based delineation of stereotactic lung targets: the influence of image modality and target size on interobserver variability. Int J Radiat Oncol Biol Phys. 2012;82:e265-e272.

13. Hawkins MA, Brooks C, Hansen VN, et al. Cone beam computed tomography-derived adaptive radiotherapy for radical treatment of esophageal cancer. Int J Radiat Oncol Biol Phys. 2010;77:378-383.

14. Yoo S, Yin FF. Dosimetric feasibility of cone-beam CT-based treatment planning compared to CT-based treatment planning. Int J Radiat Oncol Biol Phys. 2006;66:1553-1561.

15. Harsolia A, Hugo GD, Kestin LL, et al. Dosimetric advantages of fourdimensional adaptive image-guided radiotherapy for lung tumors using online cone-beam computed tomography. Int J Radiat Oncol Biol Phys. 2008;70:582-589.

16. Underberg RWM, Lagerwaard FJ, Slotman BJ, et al. Use of maximum intensity projections (MIP) for target volume generation in 4DCT scans for lung cancer. Int J Radiat Oncol Biol Phys. 2005;63:253-260.

17. Persson GF, Nygaard DE, Munck AF, Rosenschöld P. Artifacts in conventional computed tomography (CT) and free breathing fourdimensional CT induce uncertainty in gross tumor volume determination. Int J Radiat Oncol Biol Phys. 2011;80:1573-1580.
18. Wulf J, Hadinger U, Oppitz U, et al. Stereotactic radiotherapy of extracranial targets: CT-simulation and accuracy of treatment in the stereotactic body frame. Radiother Oncol. 2000;57:225-236.

19. Yeung AR, Li JG, Shi W, et al. Tumor localization using cone-beam CT reduces setup margins in conventionally fractionated radiotherapy for lung tumors. Int J Radiat Oncol Biol Phys. 2009;74:1100-1107.

20. Weiss E, Wijesooriya K, Dill SV, Keall PJ. Tumor and normal tissue motion in the thorax during respiration: analysis of volumetric and positional variations using 4D CT. Int J Radiat Oncol Biol Phys. 2007; 67:296-307.

21. Liu HH, Balter P, Tutt T, et al. Assessing respiration-induced tumor motion and internal target volume using four-dimensional computed tomography for radiotherapy of lung cancer. Int J Radiat Oncol Biol Phys. 2007;68:531-540.

22. Cai J, McLawhorn R, Read PW, et al. Effects of breathing variation on gating window internal target volume in respiratory gated radiation therapy. Med Phys. 2010;37:3927-3934.

23. Clements N, Kron T, Franich RT, et al. The effect of irregular breathing patterns on internal target volumes in four-dimensional CT and cone-beam CT images in the context of stereotactic lung radiotherapy. Med Phys. 2013;40:021904.

24. Vergalasova I, Maurer J, Yin FF. Potential underestimation of the internal target volume (ITV) from free-breathing CBCT. Med Phys. $2011 ; 38: 4$
OncoTargets and Therapy

\section{Publish your work in this journal}

OncoTargets and Therapy is an international, peer-reviewed, open access journal focusing on the pathological basis of all cancers, potential targets for therapy and treatment protocols employed to improve the management of cancer patients. The journal also focuses on the impact of management programs and new therapeutic agents and protocols on

\section{Dovepress}

patient perspectives such as quality of life, adherence and satisfaction. The manuscript management system is completely online and includes a very quick and fair peer-review system, which is all easy to use. Visit http://www.dovepress.com/testimonials.php to read real quotes from published authors. 